\title{
La escritura de epístolas y su uso como fuentes documentales en la Historia de Japam (1585-1593) del jesuita Luís Fróis: análisis comparativo de un episodio*
}

Epistles and Their Use as Documentary Sources in Historia de Japam
$(1585-1593)$ by Jesuit Luís Fróis: Comparative Analysis of an Episode

PAULA HOYOS HATTORI

Universidad de Buenos Aires

paulahoyosh@gmail.com

\section{RESUMEN}

Este artículo analiza dos documentos del corpus jesuita sobre la misión japonesa. Ambos son de Luís Fróis (1532-1597) y versan sobre el mismo episodio: la conversión al cristianismo de un joven cortesano de Bungo (Kyushu) en 1577. Una de las fuentes pertenece al género epistolar y la otra, al histórico. La comparación entre ambas revela la especificidad de cada género según las normativas de la Compañia de Jesús. Concluimos que las epistolas cumplian con los objetivos básicos del género histórico y resultaban propicias para afianzar lazos espirituales e identitarios, lo cual legitimó su sistemática publicación durante el siglo XVI. Palabras clave: Jesuitas; Historia de Japam; Japón; epistolografía; Luis Fróis

${ }^{*}$ Quisiera agradecer a la doctora Silvina Paula Vidal, de la Universidad de Buenos Aires, así como también a los evaluadores del artículo por sus pertinentes recomendaciones.

HISTORIOA XLI.1 (2017): 43-79 / ISSN 0252-8894

https://doi.org/10.18800/historica.201701.002 


\section{ABSTRACT}

This paper analyzes two documents from the Jesuit mission to Japan, both written by Luis Froiis (1532-1597). They discuss the same topic: the conversion to Christianity of a young nobleman from Bungo (Kyushu) in 1577. One is an epistle and the other deals with historic issues. The comparison reveals the peculiarities of each genre, in line with the norms of the Society of Jesus. The paper concludes that epistles were considered to strengthen spiritual and identity links, as a result of which they were widely disseminated during the $16^{\text {th }}$ century. Keywords: Society of Jesus; Historia de Japam; Japan; letter-writing; Luís Fróis

Zn 1585, el jesuita Luís Fróis (1532-1597) comenzó a escribir, desde la Emisión nipona, la Historia de Japam. ${ }^{1}$ La obra, impulsada por encargo del general de la Compañía de Jesús, Claudio Acquaviva (1543-1615), narra las vicisitudes de esa misión desde 1549, el año de su fundación, hasta $1593 .{ }^{2}$ En palabras de Joseph Wicki, quien la editó por primera vez, se trata de la historia "más completa y autorizada de la misión japonesa» ${ }^{3}$ que se haya escrito durante el siglo XVI. Por otra parte, Fróis también es autor de más de un centenar de epístolas que informaban sobre la evangelización en el archipiélago nipón a los superiores de la Compañía en la India portuguesa o en Europa, que frecuentemente circulaban en forma manuscrita o bien impresa dentro del Viejo Mundo. Buena parte de este corpus epistolar, incluido en algunas de las ediciones europeas de misivas jesuitas, fue utilizada por el propio Fróis como fuente para la redacción de su Historia. ${ }^{4}$ En este contexto, el género histórico y el epistolar se revelan en estrecho y complejo vínculo: por un lado, las cartas jesuitas devinieron fuentes documentales $y$, por otro, la prosa

1 Para una síntesis de la figura de Fróis como escritor dilecto de la misión nipona, remitimos a Palomo 2005: 61 y ss.

2 Para ahondar en la historia de la misión nipona, dentro de la extensa literatura académica que ha tratado el tema, recomendamos los siguientes trabajos, ya clásicos: Boxer 2001, Elison 1973, Bourdon 1993 y Oliveira e Costa 1999.

3 Wicki 1976: 14*.

4 Véase Fróis 1976, I: 2; este tema será retomado más adelante. 
epistolar de Fróis debió transformarse en histórica. Surgen, entonces, algunas preguntas: ¿De qué manera desarrolló el autor cada uno de estos géneros? ¿Qué cambios debió operar sobre la textualidad de las misivas para la elaboración de la Historia?

A través de las herramientas del análisis literario y, específicamente, la literatura comparada, en este artículo realizaremos una lectura relacionada de dos textos distintos de Fróis. ${ }^{5}$ Sin pretender echar luz sobre la totalidad de la prolífica obra del jesuita portugués, abordaremos un corpus reducido, que funcione como muestrario para poner a prueba nuestras hipótesis. Trabajaremos, por un lado, con los capítulos 113 y 114 del segundo volumen de la Historia de Japam y, por otro, con una epístola de Fróis datada el 5 de junio de 1577 en Usuki. ${ }^{6}$ Los unos y la otra relatan, de manera diversa, el mismo acontecimiento: la conversión de un joven cortesano de Bungo ${ }^{7}$ y la consecuente reacción de su familia, que puso en peligro la vida de los misioneros e influyó, como veremos, en los acontecimientos políticos de esa provincia nipona. Consideramos que las diferencias en la escritura de los textos facilitará la reflexión sobre la peculiaridad de cada género y su apropiación por parte de Fróis en particular.

Como marco metodológico postulamos la pertinencia del análisis literario, pues, dado que permite ubicar las especificidades de cada texto del jesuita, constituye un aporte a los estudios históricos sobre la producción y la circulación de discursos ignacianos a nivel global durante la

5 Entre las múltiples definiciones de la perspectiva comparatista aplicada al campo literario, aquí destacamos su potencial en términos interdisciplinarios, en tanto la puesta en diálogo entre las dos fuentes documentales de Fróis puede brindar matices novedosos para su interpretación en clave histórica. Para ahondar en la historia de la literatura comparada, véase Behdad y Thomas 2011.

${ }^{6}$ La misiva fue incluida en una edición de cartas jesuitas publicada en la ciudad de Évora en 1598, bajo el título de Cartas que os padres e irmãos da Companhia de Iesus escreverão dos Reynos de Iapão \& China aos da mesma Companhia da India, \& Europa, desdo anno de 1549 atè o de 1580. Consultamos la edición facsimilar, editada en dos tomos por García (1997b). En lo sucesivo, referiremos esta fuente como Cartas de Évora; en el caso de las citas, indicaremos también el número de folio.

${ }^{7}$ La antigua provincia de Bungo, en el litoral noroeste de la isla de Kyushu, ocupaba el terreno de la actual prefectura de Oita. 
segunda mitad del siglo XVI. De esta manera, a la hora de leer las fuentes documentales, haremos foco en su arquitectura textual, es decir, en el modo en que esos escritos fueron construidos con determinados protagonistas, narradores, recursos retóricos y estructuras temporales (uso de anticipaciones, ordenamiento secuencial), entre otros elementos. ${ }^{8}$ Pero antes de ingresar en el análisis textual de las fuentes, nos demoraremos en dos asuntos: la presentación de ambos textos y la reconstrucción de la normativa epistolar sostenida por el instituto ignaciano en las Constituciones de la Compañia, cuya proyección mundial configuró el contexto de escritura de las misivas de Fróis. Por último, antes de desarrollar las conclusiones, nos detendremos en la normativa ignaciana referida a la escritura de la historia a partir de la obra del jesuita Antonio Possevino (1533-1611), para establecer sus posibles vínculos con los principios historiográficos planteados por Fróis en su Historia.

Así, la perspectiva acerca de las variaciones y apropiaciones de Fróis sobre la regla jesuita en ambos géneros viene a complementarse con el horizonte del análisis textual mencionado más arriba. De esa manera, a través del diálogo interdisciplinario, procuramos realizar una lectura sobre un corpus limitado pero que, debidamente, puede ser interpretado en el marco general de la escritura ignaciana y su circulación discursiva en la Europa quinientista.

\section{LAS CARTAS DE ÉVORA Y LA HISTORIA DE JAPAM}

La fuente epistolar de Fróis que analizaremos fue incluida en la edición de cartas jesuitas impresa en la ciudad lusa de Évora en 1598. Este epistolario puede ser considerado, en palabras de José Manuel García, como «la cúpula de todas [las ediciones] anteriores», ${ }^{9}$ por su extraordinario

8 En esta línea, seguimos a Roger Chartier cuando expresa que, «contra una definición puramente semántica del texto, hay que señalar que las formas producen sentido» (Chartier 1992: 51). En el análisis desarrollado en este artículo, podemos afirmar que no solo la construcción literaria de las fuentes elegidas, sino también su edición o no en forma de libro durante el siglo XVI resultan fundamentales y condicionan la interpretación histórica que aquí podamos esbozar sobre ellas.

9 García 1997a: 20. 
volumen y por la inclusión de la mayoría de las misivas impresas en otras colecciones portuguesas del siglo XVI. En efecto, la obra reúne 209 cartas de 45 autores distintos, algunos de ellos sacerdotes formados, otros legos, recientes conversos o gobernantes paganos. ${ }^{10}$ Lejos de ser un hecho editorial aislado, esta publicación formó parte de una política sistemática de la Compañía de Jesús, que utilizó la imprenta como herramienta de divulgación y "propaganda» en la Europa católica ya desde la segunda mitad del siglo XVI.

Por otra parte, como es bien sabido, las misiones jesuitas en el extremo este asiático se desarrollaron en el marco del padroado portugués de Oriente, un acuerdo entre el imperio luso y la Iglesia católica que brindaba al primero "el derecho exclusivo de navegación y comercio» a cambio de la «evangelización de los gentiles en los dominios de ultramar». ${ }^{11}$ En el contexto de esta alianza político-religiosa, en 1540, el rey João III recibió en la corte lisboeta a los jesuitas Francisco Xavier (1506-1552) y Simón Rodrigues (1510-1579), un poco antes de que el primero se embarcara hacia la India. ${ }^{12}$ No es de extrańar, entonces, que desde 1551 una veintena de epistolarios de misivas redactadas desde las Indias Orientales fueran impresos en las ciudades portuguesas de Lisboa, Coimbra y Évora. ${ }^{13}$ Esas ediciones respondían a precisos intereses de la Compañía. Como señala Ana Fernandes Pinto, «si la correspondencia jesuita surgía como respuesta a una necesidad de organización interna y cohesión, su publicación respondía a necesidades propagandísticas». ${ }^{14}$

En efecto, el epistolario que utilizaremos como fuente reflejaba, dentro de la Europa católica, un contexto de contiendas entre órdenes religiosas

${ }^{10}$ El epistolario incluye misivas del converso Anjiro/Paulo de Santa Fe (ff. 2v-3v), del «rey» Matsuura Takanobu (f. 37r), del también «rey» Shimazu Takahisa (f. 112r-v), entre otros no-jesuitas. Para el listado completo, véase García 1997a: 38-43.

${ }^{11}$ Hosne 2013: 10.

12 Sobre la invitación de João III a los jesuitas, véase Hosne 2013: 49 y ss.; y Bataillon 2014. Sobre las ediciones fuera de Portugal, mencionamos como ejemplo que una célebre epístola de Francisco Xavier, redactada en Cochin el 15 de enero de 1544, fue impresa durante el siglo XVI en París, Roma, Venecia y Ámsterdam. Véase Ferro 1993: 153 y ss.

${ }^{13}$ Véase García 1997a.

${ }^{14}$ Fernandes Pinto 2004: 21. 
en procura de auspicios regios para el apostolado en Ultramar. Esta edición monumental, como señala Fernandes Pinto, constituyó el inicio de «una estrategia editorial adoptada de ahí en adelante por franciscanos y jesuitas», ${ }^{15}$ en el marco de la competencia entre ambas órdenes para establecer misiones en el este asiático, área del padroado portugués. Por un lado, la Compañía pretendía mantener la exclusividad para el misionado en Japón que Gregorio XIII le había otorgado en 1585; por otro, los franciscanos aspiraban a evangelizar sobre el territorio nipón sobre la base de la unificación de las coronas ibéricas de $1580 .{ }^{16}$ La colección de cartas, leída en esta coyuntura, "promovía el trabajo jesuita, ilustraba su esfuerzo de adaptación a la realidad política y social de Japón y procuraba demostrar el éxito de su actividad». ${ }^{17}$ Las Cartas de Évora, entonces, buscaban no solo informar sobre la misión japonesa, sino también -y sobre todo- argumentar en pos de la exclusividad de la Compañía en ese territorio y edificar a los lectores en la fe, es decir, reforzar sus lazos comunitarios y religiosos.

Es preciso mencionar, además, que las Cartas de Évora fueron impresas con el auspicio del arzobispo de esa ciudad alentejana, Teotónio de Bragança. ${ }^{18}$ Él fue el encargado de escribir la dedicatoria del epistolario

${ }^{15}$ Ib.: 27 .

${ }^{16} \mathrm{La}$ insistencia por parte de los jesuitas en mantenerse como única orden religiosa en Japón, a pesar de las iniciativas mendicantes desde el enclave español de Manila, buscaba evitar "conflictos entre occidentales» $\mathrm{y}$ "mantener la unidad religiosa» en Japón (Fernandes Pinto 2004: 25). Alessandro Valignano (1539-1606), visitador de la Compañía en Asia y figura que retomaremos más abajo, lo explicita en el capítulo IX de su Sumario de las cosas de Japón (1583), titulado "De cómo no conviene ir a Japón otras religiones»: «Y si ahora fuesen otras religiones con diversos hábitos, diverso modo de proceder y diversas opiniones, aunque no sea en las cosas que son de fe, como los japones no sepan hacer tanta distinción, cualquiera contrariedad que entre otros religiosos y nosotros hubiese, sin duda creerían que somos de distintas sectas» (Valignano 1954: 144). Por el contrario, al mantenerse a rajatabla la unidad de hábitos y «modos de proceder», el cristianismo a los ojos de los japoneses resultaba desprovisto de toda discusión o conflictividad, a diferencia de lo que ocurría entre las diversas escuelas budistas de la época. Sobre este último punto, véase Kitagawa 1966.

${ }^{17}$ Fernandes Pinto 2004: 28.

${ }^{18}$ Sobre el arzobispado de Bragança, véase Palomo 1994 y Serrão 2015. 
a Francisco Xavier y a Simón Rodrigues, por ser ambos representantes de la «misma conquista» de las almas paganas, llevada adelante a través de dos vías absolutamente complementarias: «embarcándose uno, y quedándose en este reino el otro, con correspondencia entre ambos para crear en el real Colegio de Coimbra [...] religiosos perfectísimos y desapegados de las cosas de la tierra, y apegados a todos los trabajos, peligros y martirios». ${ }^{19}$ Así, en el comienzo del epistolario, Teotónio hace explícita la organización de la Compañía de Jesús y la funcionalidad de la correspondencia como vínculo estratégico entre el centro europeo y la periferia de ultramar. Los destinatarios privilegiados de las cartas eran, entonces, los estudiantes de diversos colegios de la Compañía en Europa - como el de Coimbra mencionado por Bragança - que con su lectura debían prepararse para la experiencia misional. Sin embargo, sostenemos que la afirmación del arzobispo debe entenderse también en otros sentidos. La «misma conquista», leída en el marco de una edición monumental cuya circulación trascendía los lindes de la Compañía, se revela en línea con dos combates que el instituto ignaciano llevaba adelante a fines del siglo XVI: uno, de más amplio alcance, contra los reformados; y otro, específico de la cristiandad, contra las órdenes mendicantes que pretendían misionar en Japón como ya hemos señalado. Ambas contiendas confluían en la función propagandística que Fernandes Pinto le atribuye a las ediciones de epístolas jesuitas del siglo XVI.

Por otro lado, como hemos señalado ya, la Historia de Japam nació de un encargo del general de la Compañía, Claudio Acquaviva. Sin embargo, como explica Joseph Wicki, la inquietud por escribir la historia de la misión japonesa había surgido durante el generalato de Everardo Mercuriano (1514-1580), inmediatamente anterior al de Acquaviva. El historiador jesuita Giovanni Pietro Maffei (1533-1603) había sugerido a Mercuriano que «Fróis, que vivía en el Japón» y tenía «buen talento para escribir», era el indicado para abordar la difícil tarea de poner por

19 «embarcadose hum, \& ficando neste reino o outro, com correspondencia entre ambos pera criar no real Collegio de Coimbra primeiro de vossa religiâo, Religiosos perfectissimos, \& desapegados das cousas da terra, \& apostados a todos os trabalhos, \& perigos, \& martirios» (García 1997b, I: s/f). 
escrito la historia de esa misión. Tras la muerte de Mercuriano, Maffei se dirigió con las mismas intenciones a su sucesor Acquaviva, quien dio curso a esa sugerencia a través de una misiva que «es probable que haya llegado a manos de Valignano en 1583». ${ }^{20}$ Dos años más tarde, Fróis daba inicio a su tarea.

El jesuita y escritor dedicó siete años a la escritura de la Historia -el período comprendido entre 1585 y 1589, y 1594, momento en que la concluyó - . El resultado de su labor fue una obra extensa y detallada, que procuraba, según sus propias palabras, guardar la memoria de «los primeros exploradores de esta tierra y cultores de esta nueva vińa del señor», ${ }^{21}$ es decir, los precursores de la misión que para entonces ya habían fallecido. El volumen de la Historia fue juzgado por Valignano como excesivo, por lo que el visitador le solicitó a Fróis durante su estadía en Macao (1593-1594) que redujera el texto para poder enviarlo a Roma. No obstante, la síntesis nunca se llevó a cabo y los manuscritos de la Historia fueron archivados en la India hasta mediados del siglo XVIII, cuando el jesuita José Montanha mandó desde allí una copia a la Academia de Historia de Lisboa. Una vez en la capital lusa, los manuscritos fueron nuevamente archivados hasta que los investigadores jesuitas Joseph Cross (en 1894) y Georg Schurhammer (en 1923) dieron con ellos e iniciaron su divulgación en el ámbito académico, que derivó en la tardía edición crítica de Wicki (1976-1984), aquí consultada para el análisis de los capítulos de Fróis. ${ }^{22}$

La Historia de Fróis, entonces, no fue divulgada dentro ni fuera de la Compañía de Jesús sino hasta el siglo XX. En cambio, otras historias de la misión en las Indias Orientales, como las de Valignano o Maffei, circularon incluso durante el siglo XVI en forma manuscrita o impresa, tanto para difundir los pormenores de la empresa jesuita como para reforzar los lazos identitarios dentro del instituto. ${ }^{23}$ Si bien la obra

\footnotetext{
${ }^{20}$ Wicki 1976: 11*.

${ }^{21}$ Fróis 1976 , I: 1.

${ }^{22}$ En esta reconstrucción de la suerte de los manuscritos, seguimos a Wicki (1976).

${ }^{23}$ La historia de Valignano, llamada Principio y progresso de la Compañía de Jesús en las Indias Orientales, circuló en copias manuscritas desde principios del siglo XVII (Moran
} 
histórica de Fróis sin duda también tenía tales propósitos, su exclusión de toda empresa editorial contemporánea a la misión nipona resulta significativa. La explicación brindada sobre este punto por Wicki se basa en las críticas de Valignano: al parecer, a los ojos del visitador, la Historia era larga en exceso, lo cual impedía que tanto su envío a Europa como su corrección y edición fueran empresas sencillas. ${ }^{24}$ Como veremos tras analizar las fuentes documentales, también es posible sugerir que el modo en el que está organizado el relato histórico de Fróis limitaba algunas de las múltiples funciones que sí portaban, en cambio, sus misivas.

\section{LA CONFORMACIÓN DE UNA RED EPISTOLAR JESUITA}

La Compañía de Jesús, fundada por Ignacio de Loyola (1491-1556) y otros jóvenes estudiantes de teología en la Universidad de París en 1534, fue oficialmente reconocida por el Papa Paulo III en $1540 .{ }^{25}$ Desde sus inicios, los vínculos epistolares se revelaron como pilares para el buen funcionamiento de la nueva orden. Por ellos, haremos foco en su texto fundacional y reglamentario, las Constituciones de la Compañia de Jesús, para reconstruir la relevancia de lo que allí se formula como "comunicación en letras misivas» ${ }^{26}$ según la mirada de Ignacio.

En el capítulo I de las Constituciones, la Compañía incorpora un cuarto voto monástico para todos sus miembros:

Será sumamente conducente que [los miembros] [...] además del vínculo común de los tres votos [castidad, obediencia, pobreza], se obliguen con voto especial a cumplir todo lo que el actual Romano Pontífice y sus sucesores nos mandaren respecto al provecho de las almas y propagación de la fe,

1993: 233). Por su parte, la historia de Giampietro Maffei, Rerum a Societate Jesu in Oriente gestarum, fue publicada en 1571 en Dillingen.

${ }^{24}$ La Historia está organizada en tres partes. La primera cuenta con ciento dieciséis capítulos, correspondientes al período 1549-1577. La segunda narra en ciento seis capítulos los acontecimientos entre 1578-1587. La tercera ocupa ochenta capítulos que van desde 1588 hasta 1594. La edición de Wicki fue publicada en cinco tomos (Fróis 1976).

${ }^{25}$ A través de la bula papal Regiminis militante Ecclesiae.

${ }^{26}$ Loyola 1997: 611. 
y a ir inmediatamente, en cuanto estará de nuestra parte, sin tergiversaciones ni excusas, a cualquier parte del mundo adonde nos quieran enviar, o a los turcos o a cualesquiera otros infieles, aún a aquellas partes que llaman Indias. ${ }^{27}$

De este modo, el instituto ignaciano concebía la actividad misional como una prioridad, al tiempo que se declaraba en directa dependencia de Roma. Esa proyección mundial de la actividad evangelista jesuita implicaba un desafío para la organización institucional. En este sentido, Ignacio, en el mismo documento, recuerda la centralidad del «vínculo de la obediencia ${ }^{28}$ entre los miembros y el Superior. Entonces, ¿cómo mantener la verticalidad de la obediencia entre los misioneros establecidos en "cualquier parte del mundo»?

La octava sección de las Constituciones versa justamente sobre «lo que ayuda para unir los repartidos con su cabeza y entre sí», esto es, las estrategias para conectar a los misioneros entre sí y con sus respectivos provinciales, así como a estos con el general de la Compañía en Roma. $\mathrm{Al}$ ser «más difícil unirse los miembros desta Congregación [...] por ser tan esparcidos en diversas partes del mundo entre fieles y entre infieles», ${ }^{29}$ se volvía fundamental la búsqueda de estrategias comunicativas. Una salida posible ante este problema se halló en las misivas: la escritura y la lectura de cartas se volvió una actividad cotidiana para los jesuitas, y estas pasaron a corporizar una red de información a nivel mundial sin precedentes. ${ }^{30}$ Así, a través de los escritos de sus misioneros, la Compañía comenzó a recibir en sus colegios, desde la segunda mitad del siglo XVI, noticias sobre espacios tan disímiles como Perú, India, Malaca, China, Japón, Paraguay o Brasil. ${ }^{31}$

\footnotetext{
27 Ib.: 457; el subrayado es nuestro.

28 Ib.: 451 .

${ }^{29}$ Ib.: 606.

${ }^{30}$ Véase Ferro 1993.

${ }^{31}$ Baste observar el archivo jesuita en Roma (ARSI) de manuscritos autógrafos o copias de misivas redactadas desde las misiones ultramarinas. También vale mencionar el epistolario impreso en Coimbra en 1555 en el que se incluyen epístolas jesuitas redactadas desde Brasil, la India, Japón y China; véase Copia de unas cartas 1555.
} 
Como explica Paul Nelles, «la red de información jesuita tenía tres rasgos particulares: los flujos eran abundantes, seguían un ritmo regular y operaban a corta, media y larga distancia». ${ }^{32}$ En el seno de Europa y de acuerdo con las Constituciones, los hilos de la red eran múltiples y distinguían distintos niveles. Dentro de cada provincia de la Compañía, todos los colegios o casas de residencia jesuitas debían mantener informado al encargado de la supervisión de esa provincia; este constituía el nodo vincular en dos sentidos: hacia abajo, copiando las novedades relevantes de cada colegio o casa para enviar al resto de los colegios y casas, y hacia arriba, copiándolas para el general de la Compañía. Luego, para que la información de cada provincia fuese conocida por las demás, el general era el nodo vincular, encargado de hacer copiar aquellas misivas que considerara importantes para su envío al resto de los provinciales. ${ }^{33}$

Así, quienes se dedicaban al apostolado debían informar las novedades de cada misión a la cabeza de la Compañía para que, desde allí, partieran precisas instrucciones. A modo de ejemplo, en las Constituciones, Ignacio menciona que es «menester ver si conviene dar más tiempo o menos en unas missiones [sic] o en otras ${ }^{34} \mathrm{y}$, para ello, resulta necesario que «a menudo tengan avisado al Superior los que son imbiados [sic] del fructo que [allí] se hace». ${ }^{35} \mathrm{La}$ decisión acerca del tiempo «más o menos» extenso a dedicar en cada misión era tomada, en teoría, en Europa, espacio que constituía el centro de esta red de comunicaciones, pero para ello se hacía uso de la información recibida desde la periferia, es decir, desde las misiones de ultramar. Sin embargo, cabe aclarar que, más allá de esta detallada regulación sentada por Loyola en el texto fundador de la Compañía, en la práctica el arribo de las noticias estaba sujeto a los impredecibles viajes transoceánicos y, por lo tanto, con frecuencia no solo

${ }^{32}$ Nelles 2014: 52.

${ }^{33}$ Para un detallado análisis de la progresiva consolidación de la práctica escrituraria de cartas edificantes (a través de la labor de Juan de Polanco) y su circulación tanto manuscrita como impresa en el seno de la Compañía en la segunda mitad del siglo XVI, remitimos al ya citado trabajo de Nelles (2014).

${ }^{34}$ Loyola 1997: 600.

${ }^{35} \mathrm{Ib}$. 
las decisiones organizativas sino también las estrategias apostólicas eran mentadas en el terreno de cada misión. ${ }^{36}$

Esta función reguladora de las misivas no era la única. Por el contrario, como analiza Nelles, la escritura jesuita también «desempeñaba numerosas funciones psicológicas, pastorales y espirituales que no se distinguían fácilmente de los usos administrativos de la información». ${ }^{37}$ Como ahondaremos a continuación, la edificación cuenta entre esas funciones, a la vez identitarias y espirituales, al tiempo que significativamente remite a la retórica paulina.

\section{LA FUNCIÓN EDIFICANTE DE LAS EPÍSTOLAS JESUITAS}

También en la octava parte de las Constituciones, Ignacio señala que los provinciales debían divulgar aquellos fragmentos de las epístolas que llevaran a la "edificación» ${ }^{38}$ de sus receptores. Estas misivas, que «se situaban en el núcleo ideológico» de la estrategia comunicativa de los ignacianos, «describían la experiencia jesuita y proporcionaban ejemplos reales de la práctica apostólica» ${ }^{39}$. El objetivo edificante de las cartas, además, emparentaba la escritura jesuita con la tradición epistolar de San Pablo, quien se erigía como punto de referencia e identificación para los nuevos apóstoles de las Indias. ${ }^{40}$

${ }^{36}$ Remitimos al análisis de Moran (1993) acerca de los problemas de comunicación entre el visitador de la Compañía en Asia, Alessandro Valignano, y el prepósito general en Roma, Everardo Mercuriano. Frente a la certeza del visitador de que «la información del general nunca estaba completa ni actualizada», Valignano "debía considerar aquello que el General había escrito [en sus cartas], y luego decidir por sí mismo lo que había que hacer» (Moran 1993: 24).

37 Nelles 2014: 51.

${ }^{38}$ Loyola 1997: 611.

39 Nelles 2014: 53.

${ }^{40}$ La segunda carta a los corintios se demora en el vínculo epistolar como modo de edificar a los nuevos cristianos, ante la circunstancial ausencia física de los apóstoles: "os escribo esto ausente, para que presente, no necesite usar de la autoridad que el Señor me confirió para edificar, no para destruir» (II Cor, 13: 10). Todas las versiones en castellano de la Biblia han sido tomadas de Nácar Fuster y Colunga 1960. 
Ya desde la perspectiva de Ignacio de Loyola, era posible distinguir entre aquello que regulaba el funcionamiento de la institución y aquello que edificaba espiritualmente a los lectores, lo cual se traducía en una clasificación de la información sobre las misiones de ultramar. Así, por un lado, se encontraban los datos que solo podían ser leídos en pos del funcionamiento de la orden y que correspondían a lo que Ines Zupanov llamó nostrum de la Compañía. Por otro lado, se encontraban las historias apostólicas que revelaban su potencial capacidad instructiva en todo lector, fuera este jesuita o no, y que, en ese sentido, apuntaban también a los otros, alienum. ${ }^{41}$ Creemos que este segundo tipo de textos daba un propósito identitario a las ediciones de epístolas apostólicas que, como hemos señalado, comenzaron a ser publicadas en Europa desde la segunda mitad del siglo XVI. Con el explícito propósito de edificar, las misivas redactadas desde las periferias de la red epistolar fueron sistemáticamente corregidas, compiladas e impresas en el centro de esa red. Así, contribuyeron a la consolidación de una determinada imagen del instituto ignaciano y su vínculo con Roma en el contexto de la Europa postridentina.

Por otra parte, esta insistencia jesuita en la edificación vincula la experiencia de los misioneros del siglo XVI con la de los apóstoles de la Iglesia primitiva, San Pablo en particular. Para comprender la riqueza polisémica del término edificación y su fuerte vinculación con aquellos primeros apóstoles, podemos citar la primera epístola de Pablo a los corintios: «yo, como sabio arquitecto, puse los cimientos, otro edifica encima. Cada uno mire cómo edifica, que cuanto al fundamento, nadie puede poner otro más que el que está puesto, que es Jesucristo». ${ }^{42}$ En clave alegórica, el apóstol aparece como un arquitecto que coloca las bases de una construcción; es decir, funda en Cristo una obra cuya edificación

${ }^{41}$ Una carta de Ignacio de Loyola, dirigida a Pedro Fabro el 10 de diciembre de 1542, explicita esta diferencia y aconseja a los misioneros que escriban una carta principal, "la cual se pudiese mostrar a cualquier persona», y una carta "hijuela», con lo que concerniese únicamente a los superiores, como «enfermedades, nuevas, negocios». Véanse Loyola 1997: 649; Palomo 2005: 64 y ss.; y Zupanov 1999: 9.

42 I Corintios 3: 10-11 (Nácar y Colunga 1960: 1187-1188). 
queda en manos de los nuevos cristianos. En la epístola a los efesios, ${ }^{43}$ se desarrolla una noción similar, que agrega el sentido de que «todo el edificio» así construido constituye «un templo»: la Iglesia cristiana. Esta es entendida en esta misma duplicación: como el espacio físico e institucional de reunión y profesión y como la congregación espiritual de todos los cristianos. La edificación paulina, entonces, se revela como el proceso de consolidación de los vínculos espirituales de toda la cristiandad, esa comunidad universal concebida como un edificio.

A nuestro entender, este sentido específico del término, acuñado en los tiempos de la Iglesia primitiva, es recuperado y resignificado en el contexto de las misiones jesuitas del siglo XVI. Las Cartas de Évora insisten en esta función de la escritura apostólica y consideran el novedoso contexto de la misión japonesa como idóneo para experiencias edificantes. En palabras de Luís Fróis: «por ser las costumbres de los japones tan contrarias a las nuestras, y por estar [nosotros] en esta tierra nueva, y entre gente tan ignorante de las cosas de nuestra ley, bien se puede entender cuán frecuentemente puedan acontecer casos de mucha edificación y sorpresa». ${ }^{44}$

La edificación, que en el caso de las epístolas de Pablo apuntaba a los nuevos cristianos de los que el apóstol se encontraba físicamente alejado, ${ }^{45}$ en las Cartas de Évora procura llegar a un público mayor, extendido a otros misioneros, a los jesuitas que eventualmente podían devenir misioneros, y también a los cristianos europeos, potenciales lectores de la colección de cartas. Este ampliado horizonte de lectores debe interpretarse en el contexto específico de la crisis religiosa que sobrevino a la Reforma luterana y el posterior quiebre irreversible de la cristiandad europea.

\footnotetext{
43 Efesios 2: 19-21 (Nácar y Colunga 1960: 1216).

${ }^{44}$ En las citas de las fuentes, incluimos en el cuerpo del texto nuestra traducción al castellano, y en nota al pie el original portugués. «Dos costumes dos Japóes [ser] tam contrarios aos nossos, \& de estarmos em terra nova, \& entre gente tam ignorante das cousas de nossa lei, bem se pode entender quáo frequentemente possáo acontecer casos de muita edifficação, \& espanto» (García 1997b, II: 21v).

${ }^{45}$ Véanse las epístolas de la cautividad, en particular Filipenses 2: 12 y 19; y Filipenses 3: 1 (Nácar y Colunga 1960: 1221).
} 
En este sentido, estas epístolas hacen reiteradas comparaciones entre la naciente Iglesia japonesa y la Iglesia primitiva, como si el apostolado de los primeros ańos del cristianismo fuera reversionado y renovado en el marco de las labores apostólicas específicas de la Compañía de Jesús.

\section{LA CONVERSIÓN DE UN CORTESANO DE BUNGO EN CLAVE EPISTOLAR Y EN CLAVE HISTÓRICA}

Los documentos que analizaremos a continuación versan sobre la provincia de Bungo, regenteada por el clan Otomo, con capital en Funai. ${ }^{46}$ Esta ciudad había sido usada por los jesuitas como base de la misión entre 1556 y 1562, en lo que Juan Ruiz de Medina ha llamado la «época de Bungo", ${ }^{47}$ hasta que el superior de la misión, Cosme de Torres (1510-1570), decidió trasladarse al puerto de Yokoseura. El daimyo ${ }^{48}$ Omura Sumitada había donado este puerto a la Compañía en 1562; en 1563, además, se bautizó con el nombre de don Bartolomé, con lo cual garantizó su apoyo a la misión en toda su área de influencia, es decir, el litoral noroeste de Kyushu. ${ }^{49}$ Así, la comunidad cristiana de Bungo se mantuvo solo gracias a las periódicas visitas de algunos "hermanos» jesuitas hasta la llegada de Luis Fróis durante el bienio 1577-1578. Ese traslado respondía al creciente favor hacia la Iglesia del daimyo de Bungo, Otomo Yoshishige, quien, al igual que Omura, se bautizó con el nombre de don Francisco en agosto de 1578.

${ }^{46}$ En 1577, la Compañía de Jesús llevaba casi tres décadas de misionado en Japón. Con especial presencia en la región norte de la isla de Kyushu, había comunidades cristianas en Funai, Yokoseura, Hakata, Kagoshima, entre otras ciudades. Para su ubicación, véase el mapa de Kyushu inserto en este texto.

${ }^{47}$ Ruiz de Medina 1995: 25.

${ }^{48}$ Daimyo (o, en su trasliteración castellana, "daimio») es el término nipón que literalmente significa "gran señor» y que era aplicado a aquellos gobernantes que "tenían dominios cuyo producto anual según estimación oficial en términos de arroz era de más de 10.000 koku»; un koku era equivalente a un volumen de 180 litros (Tanaka 2011: 134).

${ }^{49}$ Sobre la conversión de Omura, véase Ribeiro 2009: 65-86. 
Mapa de Kyushu (siglo XVI) ${ }^{50}$

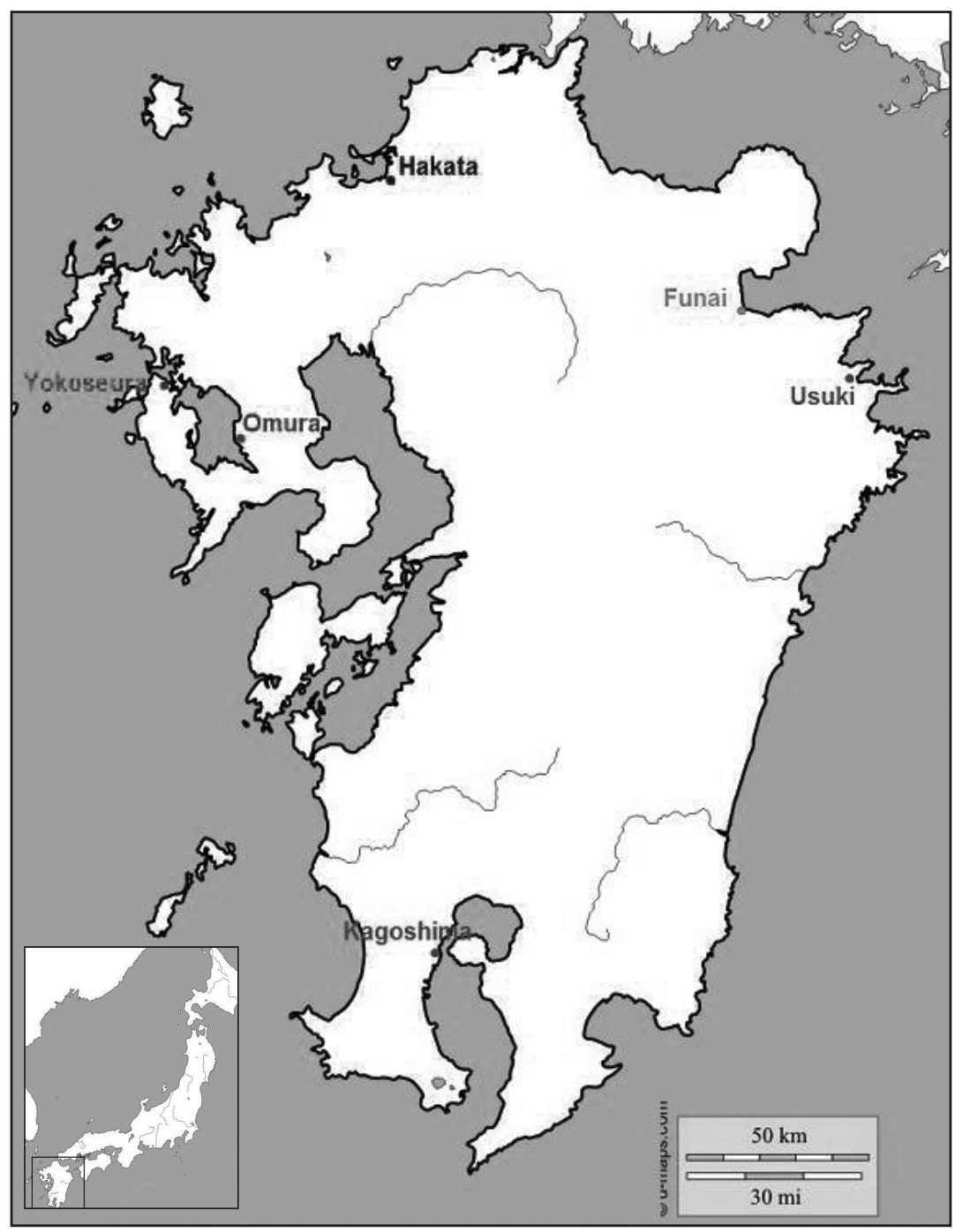

${ }^{50}$ Yokoseura y Omura se encontraban bajo el mando del clan Omura; Funai y Usuki, bajo el clan Otomo (provincia de Bungo); y Kagoshima, bajo el clan Shimazu (provincia de Satsuma). Mapa elaborado a partir de: http://d-maps.com/carte. php?num_car=1154688lang=en. Las ciudades han sido ubicadas sobre la base del mapa confeccionado por Josef Franz Schütte (García 1997a: 44-45). 
El episodio que elegimos para contrastar la prosa epistolar y la histórica es justamente la conversión de un sobrino de Yoshishige en 1577. Llamado Chicatora en los documentos, ${ }^{51}$ este joven fue el hijo adoptivo de un hermano de la mujer del daimyo. Esta es referida en las fuentes jesuitas como Jezabel, en alusión a la esposa de Ahab retratada en el Antiguo Testamento por su aversión a los profetas de Yavé y su absoluto fanatismo hacia el ídolo Baal. ${ }^{52}$ Jezabel, en las versiones de la Compañía, se erige como la gran antagonista de su joven sobrino y de los misioneros que lo apoyan en su conversión. Para analizar mejor este episodio en las dos fuentes escogidas, podemos sintetizarlo en una secuencia tripartita: (1) la formación cristiana y conversión de Chicatora con el nombre de don Simón; (2) la persecución de Jezabel y su hermano Chicacata, ${ }^{53}$ padre del converso, contra los jesuitas; y (3) la intervención de Otomo Yoshishige, marido de Jezabel y tío del converso, en favor del cristianismo.

En el próximo apartado nos abocaremos a analizar las particularidades de la prosa epistolar de Fróis, para luego ingresar en el análisis de los capítulos de la Historia de Japam.

\section{La edificación en la versión epistolar del episodio}

Fróis encabeza la carta que examinaremos con las siguientes palabras: «Por el gran gusto y consolación en el Señor que hemos entendido reciben ustedes con las nuevas de Japón, gustará en extremo [...] relatarles en esta detalladamente una de las grandes cosas que hasta ahora han acontecido en estas partes, y de la que no poco se podrán edificar». ${ }^{54}$ Como se ha señalado, esta función edificante de las epístolas redactadas desde las misiones era reivindicada por Ignacio en las Constituciones de

${ }^{51}$ Ese es el nombre con el que aparece en la fuente jesuita, su nombre nipón es Shikatsura (Fróis 1976, II: 484). En este caso mantendremos la grafía de la epístola impresa en Évora. 52 Véanse I Reyes 18-21 y II Reyes 9 (Nácar y Colunga 1960: 376-382 y 393-394).

53 Su nombre nipón es Tawara Shikasada (Fróis 1976, II: 483).

54 «Polo grande gosto \& consolaçáo em o Senhor, que temos entendido receberem com as novas de Japão folgara em estremo agora de se me offerecer tempo, \& quietação pera nesta lhe relatar miudamente hua das grandes cousas que atè agora acontecerão nestas partes, e de que não pouco se poderão edifican» (García 1997b, I: 374r; el subrayado es nuestro). 
la Compañia de Jesús y aludía a la tradición epistolar paulina. Ahora bien, en la carta sobre la conversión de Simón, ¿qué elementos aportan a esta funcionalidad que organiza la prosa epistolar de Fróis? Creemos que son aquellos elementos que vuelven ejemplar la historia de Simón a los ojos de cuatro colectivos: los cristianos japoneses de Bungo, los paganos japoneses, los misioneros jesuitas y, por último, los potenciales lectores europeos, religiosos o no, de la epístola. El valor ejemplar en el episodio, además, radica en la constancia en la conversión por parte de Chicatora/Simón, incansablemente puesta a prueba por Jezabel y Chicacata. En ese sentido, la estructura narrativa de la epístola, que desglosaremos a continuación, se organiza de forma binaria: entre (1) los obstáculos presentados por los perseguidores y (2) las reafirmaciones en la fe del joven converso, apoyado por la Iglesia.

Jezabel encabeza la empresa anticristiana en el reino de Bungo y, desde el nombre que le asignan los jesuitas, aparece como una figura vinculada con la tradición judeo-cristiana. La llaman «Jezabel», en palabras de Fróis, "porque en el odio que tiene hacia las cosas de Dios y aborrecimiento a la propagación de la fe, no se diferencia de la otra», ${ }^{5}$ es decir, del personaje bíblico. Simón, por otra parte, es presentado como un joven con dotes extraordinarias para el arte, los estudios y la milicia que, según el escritor jesuita, le fueron brindados por providencia divina. ${ }^{56}$ Tras escuchar la prédica cristiana por primera vez, el joven decidió convertirse, pero al enterarse su padre, lo envió a otra provincia "para que allí no tuviese

55 «porque no odio que tem às cousas de Deos, \& aborrecimento á dilatação da fé, não se differença da outra» (García 1997b, I: 374r).

${ }^{56}$ Dice la carta: «Parece que para lo que más adelante iría a ser, ordenó nuestro Señor que concurriesen a él todas las buenas partes que se podían desear, porque además de ser agradable a todos la fisonomía de su rostro, en todas las cosas en que el padre lo mandó a estudiar, esto es: tocar instrumentos de música, cantar, leer, escribir, pintar, esgrimir, y los demás ejercicios del arte militar, en brevísimo tiempo afirmaban los maestros que los aventajaba» («Parece que pera o que ao diante avia de ser, ordenou nosso Senhor que concorressem nelle todas as boas partes que se lhe podião desejar, porque alem de ser aceita a todos a fisionomia de seu rosto, em todas as cousas em que o pai o mandou ensinar, sc. em tanger instrumentos de musica, em cantar, ler, escrever, pintar, esgrimir, \& nos mais exercicios da arte militar, em brevisssimo tempo se affirmáo os mestres que os exedia com grande aventagem»; García 1997b, I: 374r). 
quién lo ayudase en las cosas de $\operatorname{Dios}{ }^{57}$ y desistiese de su voluntad. Sin embargo, Francisco Cabral, sacerdote superior de la Compañía en Japón desde 1570, logró hacerle llegar una epístola, en la que lo alentaba a mantenerse firme en su decisión de ser cristiano. A su regreso a Bungo, Chicatora fue "a oír las últimas prédicas del catequismo", eligió el nombre Simón y, "como los cristianos de la primitiva iglesia», finalmente fue bautizado. ${ }^{58}$

Desde este momento de la narración, se inicia en la epístola la dinámica secuencial antes mencionada, con un in crescendo en las persecuciones por parte de Jezabel, quien le envió recados para que abandonara la fe cristiana, lo amenazó y, finalmente, desterró a sus compañeros cristianos y lo dejó desprovisto de criados. Frente a todas estas pruebas, Simón se mantuvo inmutable y «no había quien no le tuviese envidia, diciendo que tenían por cosa muy maravillosa la constancia de su fe en el medio de tantos combates y persecuciones tan prolongadas, careciendo totalmente de toda ayuda humana». ${ }^{59}$ A pesar de la soledad y aislamiento en el que se encontraba, los jesuitas lograron enviarle «la vida del glorioso mártir San Sebastián [...] para que aquel vivo ejemplo de los santos le esforzase más su ánimo en la fe». ${ }^{60}$ La biografía de un mártir de los primeros siglos del cristianismo europeo funcionaba en este marco como «vivo ejemplo» y posibilitaba la identificación entre el japonés converso y el santo cristiano, idea que más abajo veremos reforzada en la epístola de Fróis.

57 «Pera que ali não tivesse de quem nas cousas de Deos podesse ser ajudado» (García 1997b, I: 374v).

58 «Veo Chicatora finalmente aquí a ouvir as ultimas pregações do catequismo que lhe faltavão, \& offerecendolhe alguns nomes pera que delles escohlesse o que lhe mais quedrasse, pareceolhe bem Simão [...]. Como os christâos da primitiva igreja, ainda depois disto se passarão alguns dias em que se lhe dilatou o bautismo por ser assi necessario pera maior bem de sua alma» (García 1997b, I: 375v; el subrayado es nuestro).

59 «Não avia quem não lhe tivesse enveja, dizendo que por cousa mais maravilhosa tinhão a constancia de sua fè no meo de tantos combates, \& perseguiçóes em tam prolongado tempo, carecendo totalmente de toda a ajuda humana» (García 1997, I: 377r).

60 «o padre lhe mandou a vida do glorioso martir S. Sebastiáo [...] pera que aquelle vivo exemplo dos santos lhe esforçasse mais seu animo na fé» (García 1997, I: 376r). 
La siguiente estrategia por parte de Chicacata para disuadir a su hijo fue interpelar directamente a la Compañía de Jesús. Para ello, le envió una carta al superior de la misión en Japón, el ya mencionado Cabral, en la que se comprometía a colaborar con la Compañía si esta lograba hacer desistir a Simón de su conversión. Además, planteaba tres problemas: (1) que su hijo, desde que se convirtiera al cristianismo «le desobedeció en muchas cosas»; (2) que la nueva religión menoscababa la imagen de Chicatora, "persona tan ilustre»; y (3) que, a causa de la conversión del joven, los templos sintoístas y budistas se quedarían sin adeptos ni renta. ${ }^{61}$ La respuesta del jesuita, también relatada en discurso indirecto en la epístola de Fróis, esgrime concretos argumentos para cada punto planteado por Chicacata. Sobre el primero, Cabral explica que Simón fue instruido para que «se sometiera en todo a la obediencia [de su padre], por entender que con eso hacía servicio a Dios»; ${ }^{62}$ es decir, explicita la obediencia a la autoridad temporal como virtud cristiana. Sobre el segundo asunto, el jesuita señala que, lejos de menoscabar el buen nombre de Simón, el cristianismo lo ensalza, pues en Europa,

en cuya comparación Japón era una pequeña isla de la que hacía poco tiempo se tenía noticia, había reyes cristianos más poderosos de lo que era el rey de todo Japón, y la mayor honra de todos estos reyes y príncipes del mundo era la frecuentación de la iglesia, adonde iban a reconocer por Señor al Creador del universo. ${ }^{63}$

${ }^{61}$ El sintoismo (神道, Sinto, literalmente «camino de los dioses») es la religión aborigen de Japón, que se basa en el culto animista hacia la naturaleza; su cosmogonía puede consultarse en el Kojiki (723 d. C.). El budismo es la tradición religiosa hindú que llegó al archipiélago japonés desde el Asia continental hacia el siglo VI d. C. Ambas tradiciones convivían en Japón al momento de la llegada de los jesuitas, como lo continúan haciendo en la actualidad. Véanse Kitagawa 1966 y Conze 2013.

62 «se sometera em tudo a sua obediencia, por entender que naquillo fazia serviço a Deos» (García 1997b, I: 377r).

${ }^{63}$ «nos reinos de Europa [...] em cuja comparação Japão era hua pequena ilha de que de poucos tempos pera cà se tinha noticia, avia reis Christáos mais poderosos do que era o de todo o Japão, \& que a maior honra de todos estes reis, \& principes do mundo era a frequentação da igreja aonde hiáo reconhecer por Senhor ao Criador do universo» (García 1997b, I: 377v). 
Finalmente, sobre el tercer y último punto, Cabral recuerda la política religiosa de Oda Nobunaga, primer unificador y, al momento, el más poderoso señor del archipiélago japonés, quien «era el mayor destructor de kami y hotoke y de las sectas de Japón». ${ }^{64}$

Esta extensa exposición incorporada en estilo indirecto en la misiva de Fróis es funcional a la formación de sus destinatarios manifiestos - los jesuitas de Europa-, pues los informa sobre el tenor de las disputas con los opositores al cristianismo en Japón. Funciona como una muestra de los desafíos de esa misión en particular y del complejo entrenamiento necesario para llevarlos adelante. En los tres argumentos esgrimidos por Cabral, se conjugan el conocimiento de la lengua y de la actualidad política japonesa, la apelación a la moral cristiana y el ardid retórico de aludir a la grandeza de la Europa católica, en ese momento imposible de comprobar por parte de los japoneses. ${ }^{65}$

Tras la respuesta de la Compañía, Chicacata, respaldado por su hermana Jezabel, prosiguió a través de sus epístolas con amenazas acerca de la destrucción de la Iglesia y el asesinato de los cristianos. Ante esto, Fróis nota la diferencia entre los bonzos budistas y los misioneros cristianos:

La reina [Jezabel] y Chicacata se fundaron para hacer estas amenazas tan crudas en la costumbre de Japón, la cual es que como los señores hacen las amenazas a los bonzos, y los ponen en aprietos, o les desamparan los templos y les quitan las rentas, [los bonzos] se van por ahí desterrados con temor a la muerte [...] y piden que les perdonen [...]. De manera que supusieron que los padres iban a seguir el mismo camino, y que la cosa no llegaría al extremo al que llegó. ${ }^{66}$

64 «Nobunanga [...] era maior destruidor de Cámis, \& Fotoques, \& das seitas de Japão, do que nunca ouve» (García 1997b, I: 377v). Los «Cámis» son las deidades kami del Sintoísmo; los «Fotoques» (Hotoke) corresponden a las del Budismo. Sobre Oda Nobunaga (1534-1582) y el proceso de unificación del Japón, véase Tanaka 2011: 123-180. ${ }^{65}$ En 1582, el visitador de la Compañía Alessandro Valignano (1539-1606) envió a Roma una embajada con cuatro jóvenes japoneses cristianos, de familias nobles de la isla de Kyushu, con el explícito objetivo de que «cuando regresen, puedan dar un Japón testimonio de la grandeza y gloria de la religión cristiana» (García 1997b, II: 17v). Para mayor detalle sobre esta embajada, véase Brown 1994: 872-906.

${ }^{66}$ «Fundouse a rainha, \& o Chicacata em fazerem estas ameaças tam cruas no custume de Japão, o qual he que, como os senhores fazem as ameaças aos Bonzos, \& os poem 
Una gran diferencia entre los bonzos budistas así retratados y los jesuitas radicaba en que los segundos «trocaron las cosas temporales por las eternas, y ninguna les parece grande ni digna de ser estimada, sino Dios». ${ }^{67}$ Esto explica que las amenazas de Chicacata no funcionaran con los misioneros como interlocutores.

Este desapego de los cristianos por las cosas temporales anticipa el asunto que ocupa la segunda mitad de esta misiva y que aporta significativamente a su condición edificante: el deseo de Simón y de todos los cristianos de Bungo de «morir con los padres» si fuesen atacados por Chicacata y Jezabel. Tras un intento de engañar a Simón para que abandonara la fe cristiana mientras estaba incomunicado, «se divulgó que Chicacata mandaba gran poder de gente para destruir la iglesia, y matar a los padres». ${ }^{68}$ Ante el inminente ataque, en la iglesia comenzaron las «misas, oraciones, letanías, ayunos, sin ninguna tristeza, sino antes alegría y extraño contento». ${ }^{69}$ La casa de la Compañía devino así en un inesperado punto de encuentro de los cristianos japoneses que, ante los pedidos de los jesuitas de que se pusieran a salvo, respondían que «juntamente con los padres ofrecerían las cabezas a la cuchilla» y deseaban ser "participantes de la gloriosa corona de los mártires». ${ }^{70}$ Este «fervor de ser mártires» creció con el correr de los días, con efectos diversos: alegría entre los cristianos, sorpresa entre los paganos, consuelo

em aperto, ou desemparão os templos, $\&$ rendas que tem, $\&$ se vão porhi desterrados com temor da morte [...] pedem que lhes perdoem. Demaneira que cuidarão que avião os padres de seguir o mesmo sio, \& que não avia a cousa de chegar a tamanho estremo como chegou» (García 1997b, I: 378r).

67 «trocarem cousas temporaes polas eternas, $\&$ nenhuma lhe parecer grande, nem dina de ser estimada, senão Deos» (García 1997b, I: 378r).

68 «Logo naquelle dia se divulgou que Chicacata mandava grande poder de gente pera destruir a igreja, \& matar os padres» (García 1997b, I: 380r).

${ }^{69}$ «em nenhum [cristiano] se sentia tristeza, ou pusilanimidade alguma, antes alegria, \& estranho contentamento» (García 1997b, I: 380r).

70 «juntamente com os padres offereceriāo as cabeças ao cutelo»; «tinhão por sem duvida que Deos nosso Senhor juntamente com os padres, \& irmãos os faria participantes da gloriosa coroa dos martires» (García 1997b, I: 380v). 
entre los misioneros y, podemos agregar, edificación entre los lectores europeos de la epístola. ${ }^{71}$

Fróis interpreta este episodio como la confirmación de un versículo Mateo: «et eritis odio omnibus hominibus propter nomen meum» $;^{72}$ y como una prueba para los propios jesuitas, que debían «fortalecer las armas de la oración y la confesión» para ser dignos del martirio. Este es el punto de mayor tensión en el conflicto que relata la epístola, cuya resolución se pospone por la súbita interrupción del hilo narrativo a causa de la inclusión de una misiva de otro autor: el «rey» de Bungo, esposo de Jezabel.

Este personaje, Otomo Yoshishige, ${ }^{73}$ había sido nombrado en la epístola de Fróis solo una vez, como defensor de la libertad de cultos en su territorio. Al comenzar la persecución contra Simón, este tío suyo declaraba que «las cosas de las leyes [religiosas] eran libres, y estaba en la voluntad de cada uno escoger lo que mejor le pareciese». ${ }^{74} \mathrm{Sin}$ embargo, no había aparecido como un actor a la par de su mujer Jezabel o su cuñado Chicacata, sino que, hasta la inclusión de esta carta, ocupaba un lugar secundario en la trama que estamos reconstruyendo. En cambio, desde la incorporación de su documento en la carta de Fróis, el «rey» pasa a ser narrador (pues su misiva aparece en primera persona) y también

${ }^{71}$ Los martirologios o compendios de la vida de mártires constituyeron un género frecuentemente impulsado por la Compañía de Jesús el siglo XVII, también en el marco de la Contrerreforma. Como explica Federico Palomo en su análisis de la obra del ignaciano António Francisco Cardim, "los relatos, grabados y frescos acerca de los sujetos que habían muerto por la fe en contextos como el americano o el asiático, pronto se convertirían - junto a sus correligionarios de Inglaterra o Irlanda - en un medio eficaz con el que los jesuitas no solo trataron de reforzar las identidades del grupo. Al mismo tiempo, buscaron incentivar entre los miembros de la Orden una vocación al apostolado» (Palomo 2015).

72 «Y seréis odiados de todos por causa de mi nombre» (Mateo 10: 22; citado en García 1997b, I: 380r).

${ }^{73}$ Otomo Yoshishige (1530-1587) era daimyo de Bungo, y se convirtió al cristianismo en 1578 con el nombre de don Francisco, como veremos en el análisis de la Historia de Japam de Fróis; véase Ribeiro 2009: 127-154.

74 «As cousas das leis erão livres, \& estava na vontade de cada hum escolher o que lhe milhor parecesse» (García 1997b, I: 378r). 
potencial agente de resolución de este conflicto (dado que se perfila como incondicional defensor de los cristianos de Bungo). ${ }^{75}$

Luego, el procedimiento de incluir otras cartas dentro de la carta se repite, en un movimiento que pluraliza las voces del texto. ${ }^{76}$ Otros dos personajes, que hasta entonces también eran secundarios, toman la voz en la epístola de Fróis para señalar su respaldo a Simón, en particular, y a la misión cristiana en Bungo, en general. Ambos son hijos de Otomo Yoshishige: el primogénito, heredero del reino, Otomo Yoshimune; y el segundogénito, convertido al cristianismo con el nombre de don Sebastián. El argumento principal tanto de Otomo como de sus hijos para apoyar la conversión de Simón es la compatibilidad entre la profesión de una fe extranjera y la obediencia a las autoridades temporales locales. La misma idea es subrayada por Francisco Cabral, autor de una cuarta epístola dentro de la epístola de Fróis, en la que dice:

así como en el primero de los tres mandamientos que versan solamente sobre el culto divino, Dios nuestro seńor quería ser honrado y amado sobre todas las cosas, así en los siete que versan sobre lo manifiesto, puso como cabeza y regla de todos los demás la obediencia, la veneración y el servicio que se debe a los padres, reyes y señores temporales. ${ }^{77}$

${ }^{75}$ Dice en la carta: «si los trabajos e injurias que se hacen contra los padres en los reinos extraños de Japón, que no son de mi jurisdicción, yo las tomo como si fuesen ofensas a hechas contra mí, cuánto más he de creer que las sentiré aquí, donde los tengo entre mis brazos» («se os trabalhos, \& injurias que se fazem aos padres nos reinos estranhos de Japão, que não são da minha jurdição, eu as tomo como se fossem offensas a mim feitas, quanto mais he de crer que as sentirei aqui onde os tenho nos braços»; García 1997b, I: 383v).

${ }^{76}$ Esta cualidad polifónica de la carta de Fróis puede atribuirse en términos generales al corpus jesuita redactado desde misiones de Ultramar, en tanto incorporan testimonios de otras personas, tanto escritos (como en el caso que estamos analizando) como orales. Sobre este punto, véase Ginzburg 1999.

77 «assi como no primeiro dos tres mandamentos que tocão ao culto divino, Deos nosso Senhor queria ser sobre toda sas cousas honrado, \& amado com todas as forças, assi nos sete que tocão ao proximo pos como cabeça, \& regra de todos os mais, a obediencia, veneração \& serviço que se deve aos pais, reis \& senhores temporaes» (García 1997b, I: 385r). 
En el contexto de las guerras intestinas que dividían Japón durante la «Época de los Estados en Guerra» (sengoku jidai), la obediencia a los superiores era útil a los grandes señores japoneses, fueran o no conversos. ${ }^{78}$ De modo que este valor cristiano se esgrimió como argumento estratégico para el cese de las persecuciones y la tolerancia hacia los evangelizadores jesuitas, no solo en este caso en particular sino también en muchos otros a lo largo de la historia de esa misión.

Luego de que Otomo Yoshishige y sus dos hijos respaldaran a través de epístolas la conversión de Simón, el conflicto terminó. Fróis ofrece una interpretación de la resolución del episodio aludiendo nuevamente a la metáfora de la edificación de la Iglesia japonesa: «a muchos extremos llegó el demonio para derrumbar esta columna, y con ella deshacer lo que por cerca de treinta años se ha edificado en Bungo, pero los males que con esto pretendía, los convirtió nuestro Señor a todos en bien». ${ }^{79}$ Así, las persecuciones a Simón y a los cristianos no solo reafirmaron en la fe a los conversos japoneses, sino que también hicieron que «el mal concepto y la opinión que los gentiles tenían acerca de la Cristiandad se convirtieron en admiración y sorpresa». ${ }^{80}$ Un tercer efecto favorable fue la demostración del favor de Yoshishige hacia los jesuitas. Sobre este punto, cerca del final de la misiva, Fróis cita una última epístola del daimyo, en la que este declara tener «otras cosas guardadas en mi pecho, que el tiempo poco a poco irá descubriendo», en referencia a la fe cristiana a la que se convirtió un año después de este episodio.

Finalmente, Fróis se despide de sus destinatarios de la Compañía con palabras a la vez de aliento y advertencia acerca de la misión japonesa:

${ }^{78}$ Sobre el Sengoku Jidai, véase Tanaka 2011: 118 y ss. Sobre la incidencia de los misioneros en los conflictos bélicos de la isla de Kyushu durante la segunda mitad del siglo XVI, véase Elisonas 2008.

79 «Muitos estremos fez o demonio pera derrubar esta columna, \& com ella desfazer, o que perto de trinta annos se tem edificado em Bungo, mas os males que nisto pretendia seguiremse, converteo nosso Senhor todos em bem» (García 1997b, I: 385r).

${ }^{80}$ "O mao conceito, \& a opinião que os gentios da Christandade tinhão, se converteo em admiração, \& espanto» (García 1997b, I: 385v). 
sin duda es necesario, así a los que de allá vendrán, como a los que ya andan por acá, ocupados en la obra de la conversión, además de mucha resignación, humildad, fe y confianza en Dios, considerar cada uno de los días de la vida como el último, y así ayudarán a la frecuencia de la confesión y comunión, como personas que cada día y cada hora esperan la muerte. ${ }^{81}$

El desapego a lo temporal, antes reivindicado en la epístola como una virtud cristiana, aquí cobra una significación específica para la práctica apostólica. Ante la magnitud de las pruebas y persecuciones, los misioneros deben estar prestos a perder la propia vida y concebir tal transe como la mayor dignidad: el martirio. Con esta reflexión, Fróis subraya la premisa edificante con que había dado inicio a su epístola y marca a los jesuitas de Europa — potenciales misioneros en Asia- como destinatarios privilegiados de su documento.

\section{Organización temporal en la clave historiográfica}

Los capítulos 113 y 114 de la Historia, titulados «De las cosas que acontecieron en Bungo sobre la conversión de Xonoxirondono Simón, hijo adoptivo de Chicacata» y "De lo demás que en este negocio hizo Chicacata y del fin que tuvieron las cosas de Simón», presentan el mismo episodio que la epístola que acabamos de analizar. El primer gran contraste que podemos remarcar entre ambos documentos es que, en este caso, ambos títulos brindan un resumen sobre el contenido del episodio, mientras que el encabezado de la epístola solo indicaba el autor (Fróis), la data (Usuki, 5 de junio de 1577) y los destinatarios (los miembros de la Compañía en Portugal). Los títulos de los capítulos también revelan que la organización de la Historia combina la variable temporal con la temática, a diferencia del epistolario, en el que la cronología de las

81 «necessario he sem duvida assi aos que de lâ vierem, como aos que já ca andão ocupados na obra da conversao, alem da muita resinhação, humildade, fe, \& confiança em Deos, ter cada hum dos dias de sua vida polo derradeiro, $\&$ assi se ajudarem da frequencia da confissão, \& comunhão, como pessoas que cada dia, \& cada hora esperão pola morte» (García 1997b, I: 386v). 
misivas es el único criterio para su ordenamiento. ${ }^{82}$ En estos dos capítulos consecutivos Fróis narra el episodio completo de la conversión de Simón, la persecución de Jezabel y Chicacata, y la resolución gracias a la intervención de Otomo Yoshishige. A pesar de que el episodio mantiene esta estructura tripartita, en dos puntos los relatos divergen: el retrato de los personajes y el tratamiento de la temporalidad.

Comencemos con el análisis de los retratos de personajes. El protagonista Chicatora/Simón, cuya semblanza en la carta es la de un cristiano ejemplar por la constancia y la fe, en el comienzo del capítulo 113 es retratado de un modo sutilmente distinto. Mientras que en la epístola todas las dotes extraordinarias del joven son explicadas por la providencia divina, en la Historia Fróis únicamente enumera esas cualidades, sin interpretarlas como anticipación del cristiano que Chicatora «más adelante iría a ser». Luego, al regresar del exilio forzado por Chicacata, el autor relata que «lo bautizó el padre Francisco Cabral, a los ocho días del mes de la cuarta luna del año 1577», sin plantear, como en la epístola, una comparación con los conversos de la Iglesia primitiva.

El cambio más significativo en el retrato de Simón ocupa el final del capítulo 114 cuando, lejos de ser perfilado como un perfecto y constante cristiano, Fróis señala lo siguiente:

como era joven, hirviéndole la sangre, fluctuaba en estas olas que continuamente alteraban y movían su corazón; y cuando ponía los ojos sobre las delicias, tratamientos, criados, privilegios, renta y situación anterior [...] se iba inclinando más a poner los ojos en la sombra que había dejado atrás, y no en la esperanza del infinito premio de su perseverancia. ${ }^{83}$

Esta contienda íntima de Simón explica, en la Historia, su posterior desapego respecto de la empresa cristiana, que se manifestó en el modo en

${ }^{82}$ Hay unas pocas excepciones para este criterio cronológico en las Cartas de Évora (Fernandes 2004: 41-55).

83 «Simão, como era mosso, fervendo-lhe o sangue, fluctuava nestas ondas que continuamente alteravão e movião seo coraçáo; e quando punha os olhos nas dilicias, tratamento, criados, privança, renda e estado passado [...] hia-se mais inclinado a pôr os olhos na sombra que lhe ficou atraz, que na esperança do infinito premio de sua perseverança» (Fróis 1976, II: 496-497). 
que prosiguió su vida tras este episodio: poco después, don Francisco fue vencido en batalla por otro clan, Simón huyó del reino y se casó con una pagana, alejándose de la tormentosa vida política de la isla de Kyushu. ${ }^{84}$

La Historia también guarda importantes diferencias respecto de la epístola en la representación de don Sebastián. El segundogénito de Yoshishige, en la misiva, respaldaba por completo a Simón. Para ello, le había enviado una nota a Chicacata, en la que, entre otras cosas, subrayaba «el amor y la afición» que sentía por la Iglesia. Muy por el contrario, en la Historia, este príncipe de Bungo es retratado como un simulador, que aparentaba apoyar a su primo pero ocultamente planeaba su ruina. Dice Fróis que su ayuda a Simón

no era de corazón, sino antes fingimiento y falsedad porque, como él era de diabólica naturaleza, el rey y el príncipe no podían domarlo, y le habían cortado las alas para que no se levantase [...] en los asientos de los lugares y protocolos, a don Sebastián le tocaban siempre grados inferiores [que a su primo], cosa que él apenas podía tolerar y deseaba ver a Simón totalmente excluido de aquella casa, para verse a sí mismo en ella incluido ${ }^{85}$

El apoyo hacia Simón, en lugar de estar motivado por la solidaridad cristiana, aquí es vinculado con las pretensiones personales de Sebastián de ascender políticamente en la casa de Chicacata. Creemos que este rotundo cambio en la presentación del segundo hijo de Yoshishige responde a su posterior apostasía, imposible de prever en 1577, momento de la escritura de la carta. Esto nos lleva al segundo punto de divergencia que hemos indicado: la organización temporal.

${ }^{84}$ En 1578, tras una victoria en la región de Hyuga, las tropas de Otomo fueron derrotadas por las fuerzas del clan Shimazu, de la provincia de Satsuma con capital en Kagoshima. Desde 1467, la isla de Kyushu fue foco de enfrentamientos entre diversos clanes, como Shimazu, Otomo, Mori, Omura, Ryuzoji, hasta la sumisión al poder central establecido por Hideyoshi Toyotomi en 1587. Véase Elisonas 2008: 335 y ss., y 356 y ss.

85 «Mas isto não era de coração, antes sentimento e falcidade porque, como elle era de diabolica natureza e el-rey e o principe o não podião domar, tinhão-lhe cortadas as azas para que se não alevantasse [...] nos assentos dos logares e preheminencias lhe ficava sempre Dom Sebastiáo com graos inferiores, couza que elle mal podia tollerar e dezejava ver totalmente a Simáo excluido daquella caza para se ver a si mesmo introduzido nella» (Fróis 1976, II: 494). 
Mientras la temporalidad de la prosa epistolar se centra en el pasado inmediato, la mirada histórica de Fróis abarca un arco temporal ampliado. El conocimiento del jesuita sobre lo acontecido en la misión hasta 1585 - cuando comenzó a redactar la Historia - le permite hacer uso de anticipaciones e interpretar a los personajes en vínculo con sus decisiones posteriores. Con este principio, en la versión historiográfica del episodio que analizamos, Fróis señala que el rey Otomo «todavía era gentil», en alusión a la conversión con el nombre de don Francisco, que tuvo lugar el año siguiente. También en este sentido, el primogénito de Otomo es desplazado de la acción, al punto que apenas es mencionado en dos ocasiones y no se lo cita. Este personaje desde 1578 se acercó al cristianismo, e instó a su mujer a la conversión, pero, tras la derrota de las tropas de Bungo frente a las de Shimazu, regresó a los cultos tradicionales japoneses. De modo que atribuirle un gran papel en la protección de Simón resultaba inconducente en la construcción de la primera historia oficial de la Compañía de Jesús en Japón.

Así, al conocer el devenir de la misión en los ańos siguientes, Fróis tiene la posibilidad de marcar anticipaciones y releer el pasado en clave teleológica. El corpus epistolar, que carece de esta condición, aun siendo para él una fuente fidedigna, debe ser transformado en el montaje de una historia cuyo desenlace se conoce de antemano. A continuación, veremos cómo plantea Fróis este asunto en el prólogo de su Historia y lo vincularemos con los postulados sobre el ars historicae del jesuita Antonio Possevino.

\section{LA ESCRITURA DE LA HISTORIA EN FRÓIS Y EN POSSEVINO}

En el Prólogo de la Historia de Japam, Fróis explicita su uso de fuentes y justifica la perentoria necesidad de escribir esa obra: «[de no escribirla] podía suceder que pasaran más ańos en silencio y, consumado el curso de la vida de las personas antiguas, [la historia] hubiese quedado sepultada en las tinieblas del olvido». ${ }^{86}$ La redacción de la Historia resulta ser,

86 «Podia acontecer que se passasse mais annos com silencio por ella e, acabada de se consumar o breve curso da vida destas pessoas antigas [...] ficava sepultada nas trevas 
en parte, la puesta por escrito de las «memorias de los padres, hermanos antiguos y algunos cristianos de los viejos, de aquel tiempo primitivo", es decir, de la primera etapa de la misión. Pero esos testimonios orales no son las únicas fuentes de las que se vale el autor para reconstruir el pasado. También, explica: «lo que faltase [...] se podía suplir [...] con el libro que anda impreso de las cartas anuas, que, según el orden y curso del tiempo, siempre se fueron enviando desde acá». ${ }^{87}$ Ambas fuentes, si bien una oral y la otra escrita, comparten la autopsia como criterio de fidelidad; comparten, en otras palabras, la condición de testigos oculares de sus autores, todos misioneros jesuitas que narran lo que han vivido en territorio nipón. ${ }^{88}$

Por otra parte, Fróis posee una mirada crítica sobre las fuentes de las que se vale. Sobre las misivas, seńala:

en los primeros años — por ser poca la noticia sobre la tierra, y por carecer de la experiencia que era necesaria- se escribieron algunas cosas cuyas realidades después se entendieron mejor, y así la carencia de luz que de ellas se tenía se opuso a las informaciones más modernas. ${ }^{89}$

En otras palabras, el historiador jesuita se encargó de analizar sus fuentes escritas y las comparó con los testimonios orales que fue recogiendo, según explica, en un viaje por «todas las partes principales en donde hasta ahora se ha implantado la ley de Dios en Japón». ${ }^{90}$

do esquecimento" (Fróis 1976, I: 3).

${ }^{87}$ «O que faltasse para sua perfeição [...] se podia suprir, e ajudar-nos do livro que anda impresso das cartas annuas, que, segundo a ordem e discurso do tempo, se forão de cá sempre inviando» (Fróis 1976, I: 2).

${ }^{88}$ Para mayor detalle sobre la autopsia «como técnica de indagación y recolección de información" para la escritura de la historia, que se remonta al historiador griego Polibio, véase Vidal 2010: 105. Para un análisis sobre la escritura de la historia en la Europa temprana moderna, véase Grafton 2007.

89 «nos primeiros annos - por se ter pouca noticia da terra, e carecerem da experiencia que era necessaria- se escreveráo algumas couzas das quaes depois se entendeo melhor sua realidade, e assim a carencia do lume, que dellas se tinha, fez alguma opozissão às informaçôes mais modernas» (Fróis 1976, I: 3).

90 "todas as partes principales onde athé agora se tem implantada a lei de Deos em Japão» (Fróis 1976, I: 4). 
En las escasas líneas de este prólogo encontramos condensados los principios historiográficos de Fróis: el método de la investigación (búsqueda y cotejo de las fuentes), el criterio de verdad (testimonial/autopsia) y el fundamento de la escritura (justificación de la necesidad de su Historia). Estos postulados pueden vincularse con las «reglas para investigar la fe y verdad de los historiadores", incluidas en el Apparato all'historia di tutte le Natione (1598), del jesuita Antonio Possevino (1533-1611). Esta obra, impresa en Venecia el mismo año de la publicación de las Cartas de Évora, es una versión ampliada y traducida al italiano por el propio autor de su previa Bibliotheca Selecta (1593), con especial foco en la disciplina de la historia humana. Aunque Fróis no haya podido conocer los libros de Possevino, la contemporaneidad entre ambos y su adscripción a la Compañía de Jesús legitiman que aquí los pongamos a dialogar. Además, las obras del italiano - la Bibliotheca y el Apparato - tienen como trasfondo, en la interpretación de Albano Biondi, la búsqueda colectiva de un modelo de intelectual católico que se fundara en una bibliografía y un programa de estudios (la Ratio Studiorum) acordes con las medidas derivadas del Concilio de Trento. ${ }^{91}$ En este sentido, recordemos que el instituto ignaciano enmarcó muchas de las iniciativas de la Contrarreforma, incluidas las misiones de ultramar, como herramientas para el fortalecimiento del catolicismo a nivel mundial.

En el quinto capítulo de la primera parte del Apparato, Possevino, siguiendo al humanista Justo Lipsio (1547-1610), menciona tres parámetros necesarios para determinar si confiar o no en una Historia: la verdad, la declaración o disposición de la materia, y el juicio moral del historiador. La prosa histórica de Fróis cumple con los tres requisitos: utiliza fuentes orales y escritas que coteja entre sí y con lo que él mismo ve en la misión nipona (garantía de verdad); organiza el relato de modo tal que «las razones y las causas se conozcan $"{ }^{92}$ (disposición); y explicita

${ }^{91}$ Possevino distingue, dentro de la historia, la divina, la eclesiástica, la natural y la humana; véase Biondi 1981.

${ }^{92}$ Señala Possevino sobre la «Dichiaratione»: «che non solo i successi delle cose, ma giuntamente la ragione \& le cagioni si conoscano» (Possevino 1598: 4v). 
su mirada cristiana sobre "aquello que aprueba y aquello que condena» ${ }^{93}$ (juicio moral).

Luego, Possevino añade otros tres criterios, planteados por el teólogo dominico Melchior Cano (1509-1610). Estos apuntan a la integridad de los historiadores en el tratamiento de sus fuentes, la prudencia al elegir y juzgar a los testigos, y la irrefutable autoridad que adquieren si la Iglesia les da crédito. Los primeros dos son cumplidos por Fróis en la minucia de su estudio de fuentes; el tercero, en el hecho de que fue Claudio Acquaviva, general de la Compañía en Roma, quien le encargó la escritura de la Historia de Japam.

De modo que la obra histórica de Luís Fróis se adecua a las reflexiones acerca de la escritura de la historia que, en el mismo momento de su redacción, tenían lugar en la Europa católica. Lejos de resultar producto de la casualidad, esto afianza la interpretación de Alberto Biondi, quien señala en Possevino un trasfondo de "optimismo", basado en la posibilidad de que la «escuela de la sabiduría» católica fuese expandida por «todo el mundo». ${ }^{94}$ En otras palabras, la experiencia misional en los dominios ultramarinos de los imperios ibéricos contribuía a la lucha, dentro de Europa, entre católicos y reformados. Específicamente en el seno de la Compañía de Jesús, a la que pertenecían ambos autores, esta correlación entre Contrarreforma y evangelización de Nuevos Mundos se evidencia en la conformación de la red informativa mundial que mencionamos al comienzo de este trabajo.

Por un lado, entonces, la escritura de una historia de la misión japonesa debe pensarse en el marco amplio del quiebre de la cristiandad, como aporte a la consolidación de una identidad apostólica específicamente católica y jesuita. En este sentido, la Historia de Fróis también apuntaba a la edificación de la comunidad católica mundial, a través de la divulgación de la experiencia misional en ultramar. Pero por otro lado, cabe preguntarse en este punto por las razones de que esta Historia de Japam

\footnotetext{
93 Señala sobre el «Giudicio»: «che distintamente \& lacidamente le cose si propongano; cioè, che l'historico questo approvi [...] questo condanni» (Possevino 1598: 5r).

${ }^{94}$ Biondi 1981: 73.
} 
no fuera publicada sino hasta el siglo XX. En otras palabras, ¿por qué la política editorial de la Compañía apuntó privilegiadamente a las misivas del autor y no a su obra histórica?

El motivo, a nuestro entender, debe buscarse en el hecho de que la vocación misional, expresada en las cartas en primera persona y en la inmediatez de las experiencias, se podía volver inspiradora para sus lectores. En cambio, la deliberación de la escritura histórica que hemos visto en Fróis - el orden causal de los hechos, el cambio en la percepción temporal—, aunque sí revistiera interés intelectual, no privilegiaba la evocación emocional necesaria para nutrir los valores cristianos o la vocación apostólica en los lectores. En la Historia de Japam, tanto la corrección de las primeras impresiones — cuando fueran erróneascomo la borradura del uso de la primera persona del singular tienden a alejar a los lectores de una posible identificación con los personajes allí representados. ${ }^{95}$ En las epístolas, en cambio, también la ejemplaridad de los protagonistas busca despertar esa empatía edificante con los lectores. En el caso de las cartas analizadas en este trabajo, resultaban ejemplares: el converso Simón por su constancia, su primo Sebastián por el apoyo al cristiano perseguido y el misionero Francisco Cabral por su resistencia apostólica ante las presiones de Chicacata. El ejemplo podía impulsar a la imitación, y esta descansaba en la posible identificación.

Por otra parte, el epistolario de Évora también podía ser leído como una historia oficial de la presencia de la Compañía en Japón hasta 1589, en la medida en que sus doscientas nueve misivas narran detalladamente las vicisitudes de la misión desde su fundación en 1549. En este sentido, en el capítulo XXVI de la Sexta Parte del Apparato, Possevino recomienda historias sobre «las cosas de la India» (palabra con la que aúna Asia y el Nuevo Mundo), y allí menciona también «las cartas de la India de los Padres de la Compañía de Jesús». ${ }^{96}$

${ }^{95}$ Fróis (1976) utiliza la tercera persona para referirse a sí mismo en su obra.

96 Possevino 1598: 208r. 


\section{A MODO DE CONCLUSIÓN}

En este trabajo hemos comparado la versión epistolar y la versión histórica que el jesuita Luis Fróis escribió acerca de un mismo episodio. El cotejo entre ambas nos permitió establecer una serie de diferencias que podemos sistematizar en dos grandes grupos: primero, las disimilitudes vinculadas con la temporalidad de los relatos; y segundo, aquellas relacionadas con el objetivo de la edificación cristiana, específico de la prosa epistolar. Dentro del primer grupo, se destacan dos artificios narrativos distintivos de la versión histórica: el uso de anticipaciones — como la futura conversión de Otomo Yoshishige al cristianismo-y la ilación de causas y consecuencias entre hechos no mencionados en la epístola — como la simulación de Sebastián al apoyar a su primo Simón-. Dentro del segundo grupo, notamos en la versión epistolar la reiterada alusión a cristianos ejemplares — como el converso Simón o el mártir San Sebastián- y la insistencia sobre valores cristianos - como la constancia, la obediencia o el desapego frente a lo temporal- En esta misma línea, la misiva plantea un paralelo entre la comunidad cristiana en Bungo y la paleocristiana en Europa, a través de tres procedimientos: la comparación explícita entre la conversión de Simón y las que ocurrían en la "primitiva iglesia»; la mención de la vida de San Sebastián como ejemplo para Simón; y la cita mencionada cita del Evangelio de Mateo, en alusión al anuncio de Cristo de las futuras persecuciones contra sus fieles. ${ }^{97}$

Por otra parte, analizamos la obra de Fróis en el contexto de la Compañía de Jesús. En el caso de las cartas, ahondamos en la doble funcionalidad reguladora y edificante de la correspondencia, postulada por Ignacio de Loyola en las Constituciones; en el caso de la Historia de Japam, comprobamos su adscripción a los parámetros para la escritura historiográfica presentados por Antonio Possevino, en el marco de la formación de un intelectual católico ideal.

Por último, planteamos la pregunta sobre la suerte editorial de uno y otro texto del jesuita. Mientras la misiva aquí analizada fue incluida no solo en las Cartas de Évora sino también en otras compilaciones 
del siglo XVI, la Historia de Japam no fue publicada sino hasta el siglo XX. Esta distinción nos permitió concluir que, si bien tanto las cartas como la Historia contribuían a la consolidación de una imagen positiva de la Compañía de Jesús en Europa, ciertas características de las misivas jesuitas las volvían idóneas para su publicación: eran concisas, por lo que copiarlas y remitirlas a través de varias vías al Viejo Mundo resultaba factible; y apelaban especialmente a la empatía emocional de los lectores. Las epístolas se revelaron, entonces, como portadoras de una polisemia que privilegió su divulgación frente a la de la Historia de Fróis, cuya extensión complejizaba las tareas de copia, envío, corrección y edición. Además, como hemos argumentado, las cartas también podían cumplir la función de brindar información sobre los hechos sucedidos en la misión, una función privilegiada de la Historia.

En síntesis, el prolífico autor jesuita Luis Fróis desarrolló su obra epistolar y su obra histórica en consonancia con la normativa jesuita de ambos géneros. En cada caso, apuntó a objetivos y a lectores distintos, lo cual se plasmó en la construcción narrativa del episodio aquí analizado. Estas distinciones sin embargo, no limitaron el uso de sus propias misivas y las de otros autores como fuentes testimoniales: de hecho se dedicó a investigar y reorganizar estos materiales para la escritura de su célebre Historia de Japam.

\section{BIBLIOGRAFÍA}

Bataillon, Marcel. 2014. «La implantación de la Compañía de Jesús en Portugal». En Los jesuitas en la España del siglo XVI. México, D. F.: Fondo de Cultura Económica, 321-325.

Behdad, Ali y Dominic Thomas (eds.). 2011. A Companion to Comparative Literature. Sussex: Blackwell. https://doi.org/10.1002/9781444342789

Biondi, Albano. 1981. «La Bibliotheca Selecta di Antonio Possevino. Un progetto di egemonia culturale». En La Ratio Studiorum: modelli culturale e pratiche educative dei Gesuiti in Italia fra Cinque e Seicento. Roma: Bulgoni, pp. 43-75. Bourdon, Léon. 1993. La Compagnie de Jésus et le Japon 1547-1570. París: Centre Culturel Portugais de la Fondation Calouste Gulbenkian.

Boxer, Charles. 2001. The Christian Century in Japan. 1549-1650. Manchester: Carcanet Press. 
Brown, Judith. 1994. "Courtiers and Christians. The First Japanese Emissaries to Europe». Renaissance Quarterly. Vol. 47, núm. 4: 872-906. https://doi. org/10.2307/2863218

Chartier, Roger. 1992. El mundo como representación. Barcelona: Gedisa.

Conze, Edward. 2013. El Budismo. Su esencia y desarrollo. México, D. F.: Fondo de Cultura Económico.

Copia de unas cartas de unos padres de la Compañia de Jesús que escribieron de la India, Japón y Brasil a los padres y hermanos de la misma Compañía. 1555. Coimbra: Joan Alvares.

Elison, George. 1973. Deus Destroyed. The Image of Christianity in Early Modern Japan. Cambridge: Harvard University Press.

Elisonas, Jurgis. 2008. "Christianity and the Daimyo». En The Cambridge History of Japan. Nueva York: Cambridge University Press, vol. 4, 301-372. https:// doi.org/10.1017/chol9780521223553.008

Fernandes Pinto, Ana. 2004. Uma imagem do Japão. A aristocracia guerreira nipónica nas cartas jesuitas de Evora (1598). Macau: Instituto Português do Oriente.

Ferro, João Paulo. 1993. «A epistolografia no quotidiano dos missionários jesuítas nos séculos XVI e XVII». Lusitania Sacra. Segunda serie, tomo V: 137-158.

Fróis, Luís. 1976. Historia de Japam. Lisboa: Biblioteca Nacional de Lisboa, 5 vols.

García, José Manuel. 1997a. "Apresentação». En Cartas que os padres e irmãos da Companhia de Iesus escreuerão dos Reynos de Iapão \& China aos da mesma Companhia da India, \& Europa, des do anno de 1549 atè o de 1580 (Edição fac-similada da edição de Évora, 1598). Maia: Castoliva, vol. 1, 11-45.

(ed.). 1997b. Cartas que os padres e irmãos da Companhia de Iesus escreuerão dos Reynos de Iapão \& China aos da mesma Companhia da India, \& Europa, des do anno de 1549 atè o de 1580 (Edição fac-similada da edição de Évora, 1598). Maia: Castoliva, 2 vols.

Ginzburg, Carlo. 1999. «Alien Voices. The Dialogic Element in Jesuit Historiography». En History, Rhetoric, and Proof. Hanover: University Press of New England, 71-91.

Grafton, Anthony. 2007. What was History. The Art of History in Early Modern Europe. Cambridge: Cambridge University Press. https://doi.org/10.1017/ cbo9781139196956

Hosne, Ana. 2013. The Jesuit Mission in China and Peru. Nueva York: Routledge. https://doi.org/10.4324/9780203760659

Kitagawa, Joseph. 1966. Religion in Japanese History. New York: Columbia University Press.

Loyola, Ignacio de. 1997. "Constituciones de la Compañía». Obras. Madrid: Biblioteca de Autores Cristianos, 431-646. 
Moran, Joseph Francis. 1993. The Japanese and the Jesuits: Alessandro Valignano in sixteenth-century Japan. Nueva York: Routledge. https://doi.org/10.4324/ 9780203036334

Nácar Fuster, Eloino y Alberto Colunga (trads.). 1960. Sagrada Biblia. Versión directa de las lenguas originales. Madrid: Biblioteca de Autores Cristianos.

Nelles, Paul. 2014. «Chancillería en colegio: la producción y circulación de papeles jesuitas en el siglo XVI». Cuadernos de Historia Moderna. Anejo XIII: 49-70. https://doi.org/10.5209/rev_chmo.2014.46789

Oliveira e Costa, João Paulo. 1999. O Japão e o cristianismo no século XVI. Ensaios de História Luso-Nipónica. Lisboa: Sociedade Histórica da independência de Portugal.

Palomo, Federico. 1994. Poder y disciplinamiento en la diócesis de Evora: el episcopado de D. Teotónio de Bragança (1578-1602). Tesis de doctorado en Historia. Madrid: Universidad Complutense de Madrid. . 2005. «Corregir letras para unir espíritus. Los jesuitas y las cartas edificantes en el Portugal del siglo XVI». Cuadernos de Historia Moderna. Anejo IV: Cultura 57-81.

. 2015. «António Francisco Cardim, la misión del Japón y la representación del martirio en el mundo portugués altomoderno». Histórica. Vol. 39, núm. 1:7-40.

Possevino, Antonio. 1598. Apparato all'historia di tutte le Natione. Venecia: G. Battista Ciotti.

Ribeiro, Madalena. 2009. Samuráis Cristãos. Os Jesuitas e a Nobreza Cristã do Sul do Japão. Lisboa: Centro de História Além-Mar.

Ruiz de Medina, Juan. 1995. Documentos del Japón 1558-1562. Roma: Instituto Histórico de la Compañía de Jesús.

Serrão, Vitor. 2015. Arte, religião e imagens em Évora no tempo do Arcebispo D. Teotónio de Bragança, 1578-1602. Vila Viçosa: Fundação Casa de Bragança.

Tanaka, Michiko. 2011. Historia minima de Japón. México, D. F.: Colegio de México. Valignano, Alessandro. 1954. Sumario de las cosas de Japón (1583). Tokyo: Sophia Daigaku.

Vidal, Silvina. 2010. La tradición vernácula de arte histórica en Italia. Tesis de doctorado en Historia. Buenos Aires: Universidad de Buenos Aires.

Wicki, Joseph. 1976. «Introdução». En Fróis, Luis. Historia de Japam. Lisboa: Biblioteca Nacional de Lisboa, vol. 1, 1*-45*.

Zupanov, Ines G. 1999. Disputed missions. Jesuits Experiments and Brahmanical Knowledge in Seventeenth-century India. Nueva Delhi: Oxford University Press.

Fecha de recepción: 6/V/2016 Fecha de aceptación: 6/VI/2016 